\title{
Environmental conflicts: Key issues and management implications
}

\section{Urmilla Bob and Salomé Bronkhorst ${ }^{*}$}

\section{Abstract}

Environmental conflicts have emerged as key issues challenging local, regional, national and global security. Environmental crises and problems throughout the world are widespread and increasing rapidly. In relation to these concerns, the article discusses the following aspects: people and the environment, environmental conflicts, climate change and environmental conflicts, and management implications. The section on people and the environment illustrates the range of ecosystems services provided, interactions, relationships and issues pertaining to access. Specific key types of conflicts as well as the main manifestations and implications of these conflicts are examined in the next section, which includes biodiversity, environmental air quality, forestry, water, land and natural resource management conflicts. This is followed by a discussion of the impacts of climate change in relation to environmental conflicts. Finally, the discussion focuses on managing environmental conflicts. Key aspects of the final section pertain to available tools and approaches, and recommendations arising from the articles in this issue.

\footnotetext{
* Prof Urmilla Bob is Associate Professor in the Discipline of Geography, School of Environmental Sciences at the University of KwaZulu-Natal, Durban.

Salomé Bronkhorst is Coordinator of the Knowledge Production Department at ACCORD.
} 


\section{Urmilla Bob and Salomé Bronkhorst}

\section{Introduction}

The association between the environment and conflicts is varied and complex. The causes of environmental conflicts vary across the globe and their manifestations differ considerably. Causes can range from control over vital environmental resources such as fossil fuels to contestations over natural resources at the community and/or household level. Conflicts can manifest in various ways - from outright wars and even genocide to disagreements at the local level. There seems to be agreement that while conflict depends on the actions (not necessarily violent) of actors, it relates to incompatibilities. In fact, Wallensteen (2007:13-15) argues that conflict is formed of three parts: incompatibility, action and actors - and therefore a 'complete definition' of conflict is 'a social situation in which a minimum of two actors (parties) strive to acquire at the same moment in time an available set of scarce resources' (Wallensteen 2007:15).

The African Centre for the Constructive Resolution of Disputes (ACCORD 2002:4) also argues in a similar vein that conflict is:

...a state of human interaction where there is disharmony or a perceived divergence of interests, needs or goals. There is a perception that interests, needs or goals cannot be achieved due to interference from the other person(s).

Whatever form conflict takes, it is likely to have several impacts (albeit at different geographical scales) which may include physical harm to both humans and the natural resource base, impact on productivity levels and economic development more generally. The articles in this special issue highlight that environmental change and conflicts affect livelihoods and health, and exacerbate poverty and inequality, with women often carrying a disproportionate burden. The focus on environment and conflict alludes to the myriad influences that human beings exert over the earth's natural resource base and processes and to the way in which natural events, processes and even environmental protection can affect human life. There is also 


\section{Environmental conflicts: Key issues and management implications}

growing consensus in both the academic and political spheres that people are exerting increasing control over the natural environment with a range of consequences. Furthermore, the phenomenon of privatising nature in its many forms (especially land ownership) is prevalent. Humans have and continue to compete for control of the natural environment, while it is used as a sink for the effects of global economic growth. However, what is becoming clear is that the natural environment can fight back. This is most noticeable in the increase in natural hazards (droughts, floods, etc.), the concern over global warming with resultant extreme climatic events and the problems associated with invasive or alien species.

This special issue is aimed at presenting key issues relating to environmental conflicts and exploring the nexus between environmental considerations and increased conflict on the African continent. In particular, while environmental conflicts are on an increase, it remains a relatively neglected field of research. This article together with the articles in this issue highlight the importance of critically examining environmental conflicts, related impacts on both humans and nature as well as the need to consider management aspects.

\section{People and the environment}

Daily (1999, cited in Le Maitre et al. 2007:369) identifies a range of ecosystems services provided by nature, which include:

- Stabilising and regulatory processes: purification and maintenance of the gas composition of the air, regulation of the hydrological cycle, partial stabilisation of climate, moderation of weather extremes, and control of the majority of potential pest species.

- Regeneration processes: generation and renewal of soil fertility, purification of water as well as the detoxification and decomposition of wastes, pollination and dispersal of seeds/spores necessary for revegetation.

- Production of goods: food, durable materials and industrial products, genetic resources and pharmaceuticals. 


\section{Urmilla Bob and Salomé Bronkhorst}

- Life-fulfilling functions: aesthetic beauty, serenity, scientific discovery and preservation of options for the future.

This range of ecosystem services shows how critically important these processes are to the functioning of the Earth's systems and to human survival, livelihoods and lifestyles, and vice versa. Nature as a resource therefore provides, either directly or indirectly, material needs for food production, living space, health maintenance (including provision of medicines) and supply of energy and livelihood materials (Bob et al. 2008:17).

There is widespread recognition and acceptance that the Earth's resources are finite and that they operate in the context of a single yet complex and interrelated system. Steffen et al. (2004:2) state:

The environment at the scale of the earth as a whole - the passing of the seasons, the vagaries of weather and climate, the ebbing and flowing of river systems and glaciers, the rich diversity of life in all its forms - has been something within which people have had to operate, subject only to great forces of nature and the occasional perturbations of extraterrestrial origin. Earth's environment has been a bountiful source of resources as well as a remarkably stable life support system that has allowed human civilisations to develop and flourish.

There is therefore an intricate and inextricable relationship between Homo sapiens and the development of societies. Over time, the control humans have over the environment has increased considerably and today people are the main custodians and consumers of the natural environment. In fact, largely due to the sheer size of the global population and our activities, a dramatic transformation of the Earth's environment and natural systems (global change) is clear, demonstrating that the abundance of nature and its ability to adapt to and absorb human impacts are under serious pressure (Steffen et al. 2004:2). Economic activity, for example, has increased nearly tenfold between 1950 and 2000 (Steffen et al. 2004:2). During the same period, the world's population doubled from less than 3 billion to 6 billion. The world's population now is more tightly connected than ever before because of globalisation of 


\section{Environmental conflicts: Key issues and management implications}

economies and information flows (Steffen et al 2004:2). In this issue, Ahmed (2010) highlights the importance of population growth in contributing to environmental conflicts and degradation in coastal zones. Moodley et al. (2010) explore the linkages between the Rwandan genocide, high population growth and density, the struggle over land, and how a resource such as land can be manipulated to incite people to violence. These cases show that to meet the United Nations' Millennium Development Goal of halving the number of people living in extreme poverty by 2015 without using the massive resource subsidy from nature in ways that may prove environmentally catastrophic, individuals, communities and countries will have to be required to design poverty reduction strategies that are consistent with resource conservation objectives (Barrett et al. 2005:193).

On the other hand, natural or human-induced environmental conditions (including rain patterns, natural hazards such as earthquakes and tsunamis, slopes and terrain, availability of water resources, and quality of land) can also be a critical source of vulnerability and insecurity for people. Some of these conditions such as climatic conditions and natural hazards can strain household and community coping strategies. Poor communities in particular are at risk because they are exposed more frequently to such shocks and they do not usually have the necessary infrastructure and resources to cope with them. The importance of coping and adaptation capabilities is highlighted by Reuveny (2007:661): 'The key issue is not how strong a disaster is per se, but rather how strong it is relative to the ability of people to withstand it'.

Access to natural resources and assets is also vital to achieve livelihood security, especially in poor communities and households that often rely directly on natural assets to ensure daily survival and livelihoods. However, livelihood activities can often destroy the natural resource base by over-use and degradation, which can contribute to desertification, deforestation, soil erosion, declining water tables and other types of environmental damage that in turn affect livelihoods. Often, in vulnerable contexts where resources are limited, the lack of alternatives results in increased environmental degradation that leads to higher levels of poverty and risk, partly causing what is generally called the poverty trap. Often also, the resultant impacts are 


\section{Urmilla Bob and Salomé Bronkhorst}

increased household and community conflicts as individuals compete over declining resources.

In this issue, the role that vulnerability plays in conflicts is emphasised by a number of the authors. For example, Perry et al. (2010) examine how vulnerable women in particular are often disproportionately affected by environmental change and environmental conflicts because of gendered power relations, especially in terms of control of and access to resources such as land. Jaggernath (2010) examines how economic growth and industrial development, environmental racism and air pollution can lead to conflicts, when poor and marginalised racial groups suffer the environmental and health consequences of development.

In light of such interactions between the environment, people and conflicts, it is therefore important to understand how ecosystems function and respond to changes (whether natural or human-induced). As Ashton et al. (2005:449) state, 'ecological processes are important from a human-needs perspective, for the goods and services they provide'. Many environmental conflicts are related directly to this aspect as people attempt to secure control over natural resources.

In this issue, Okech (2010) addresses one element of such control, that of environmental conservation, where biodiversity is protected, often by excluding people from making use of certain environmental goods and services in a particular region. Bob (2010) also highlights the dilemma between conservation and restitution claims under land reform in Sub-Saharan Africa, where people were once forcefully relocated to free areas for conservation. Because of the complex nature of and delays in dealing with such land claims, some conservation areas have been illegally occupied (Bob 2010), likely leading to environmental degradation and fuelling of conflicts.

\section{Environmental conflicts}

Several authors (Castro and Nielson 2003; Yasmi et al. 2006) argue that conflict emerges when stakeholders have irreconcilable differences or incompatible interests, values, power, perceptions and goals. Furthermore, if unresolved 


\section{Environmental conflicts: Key issues and management implications}

or not managed, conflicts are likely to escalate and intensify. White et al. (2009:244) state: 'What distinguishes conflicts from mere disagreement is thus a behavioural expression of formerly latent attitudes where one party is perceived to take action at the expense of another party's interests'. Some examples of expressions of conflicts are threats, beating, appropriation, insurgency, skirmishes, and interstate or intrastate wars (Reuveny 2007:656). Competition for finite environmental resources, divergent attitudes and beliefs as well as institutional factors trigger and exacerbate such environmental conflicts (Hellström 2001). The issue of scarcity, whether perceived or actual, is a crucial component of understanding environmental conflicts. Broadly, scarcity conflicts characterise most environmental contestations and disputes addressed in this issue.

Numerous types of environmental conflicts are identified in the literature and include:

- Biodiversity conflicts: conflicts between people about wildlife or other aspects of biodiversity (White et al. 2009:242). This also includes conflicts relating to conservation of protected areas, green technologies as well as fair trade and patenting rights in relation to biodiversity and indigenous knowledge linked to natural resources. These conflicts can occur internationally and have serious regulatory and policy implications. Impacts on the natural resource base in terms of land clearing for development and agricultural production as well as the effects of genetically modified crops on biodiversity are important considerations as well. There is evidence to suggest that if conservation and environmental management policies are not formulated and implemented in a holistic way to balance the needs and interests of conservation and people, it can lead to conflict. For example, in this issue Okech (2010) finds that in Kenya environmental protection and management can create situations where 'people become the victims of animals' and then retaliate by killing animals for bushmeat or to protect their crops or cattle from disease and predators. Linked to biodiversity conflicts are natural resource management (NRM) conflicts. Yasmi et al. (2006:538) highlight that conflicts, many of which include violence, in NRM are on an increase and 


\section{Urmilla Bob and Salomé Bronkhorst}

are complex because of multiple actors and the wide range of issues and management strategies. However, what is important to underscore is that conflicts over environmental resources can result in violent conflicts and this can transcend nation-state boundaries.

- Coastal zone conflicts. Conflicts in coastal zones are interesting in that they could develop from a combination of other types of conflicts. In this issue, Ahmed (2010) considers such conflicts in particular and highlights that coastal areas are unique in the dynamics they produce around environmental conflicts. This has to do with high development demands, high population density, environmental degradation and importantly, poor and disjointed management to balance conservation and development. The author highlights two types of coastal zone conflicts - those related to ecosystem change and those related to coastal development.

- Conflicts disproportionately affecting women. Women are often vulnerable in the broader sense (physically, economically, socially and politically) and therefore often carry a disproportionate brunt of the effects of environmental conflicts and stress. A number of authors in this issue highlight this point. Perry et al. (2010) assert that while the actual costs of environmental conflicts on women are multifaceted and hard to measure, women often experience greater food and economic insecurity, and are affected by unsafe or illegal practices. Omolo (2010) found that women in pastoral communities in Kenya are made vulnerable through cattle raids, which are often the result of droughts. Bob (2010) also highlights that apartheid-induced land scarcity has led to women being abandoned, experiencing violence and widows being dispossessed of land.

- Conflicts about air quality and noxious pollutants. This is a key type of environmental conflict - prominent in the literature and in this issue (see Jaggernath 2010) - that relates to issues pertaining to social justice and the right to live in a healthy environment. Mix and Shriver (2007) focus on local resident perceptions and concerns. It is important to note that these studies also highlight divergent perceptions over environmental threats, 


\section{Environmental conflicts: Key issues and management implications}

which are important in terms of managing these conflicts. Furthermore, an important theme is environmental racism and the links between poverty and vulnerability. While most conflicts relate to demonstrations and legal disputes as local residents and environmental activists mobilise communities to assert their rights, there are also incidences of violent conflicts. Environmental conflicts associated with air quality issues, such as in the case of the South Durban Basin (SDB) in South Africa, often also receive considerable media attention.

Other key types of conflicts include land and water conflicts, which are discussed below.

\section{Land conflicts}

Globally, but particularly in Africa, a significant proportion of people is dependent on land to make a living. As noted by Kok et al. (2009:42):

The importance of land in conflicts relates to people's ability to make a living or make a profit. Land scarcity or ambiguous property rights can contribute to grievances and violent conflict. This is particularly the case when alternative livelihoods are absent, and is often exacerbated when communities are armed...Moreover, when land contains valuable mineral resources, conflicts can arise between local communities and those who seek control over land for resource extraction...Population growth and movement, international markets, insecure property rights and legislation, climate change, environmental degradation and a myriad other factors all appear to be variables that need to be tracked in analysing conflicts where land plays a role. Finally, desertification, unsustainable use or drought can bring communities with competing livelihoods into further conflict.

In this issue, Bob (2010) considers land conflicts in Sub-Saharan Africa. The author draws attention to the many reasons and complex interplay of issues that can lead to conflict, such as the role of power in securing land tenure and the way poverty and inequality often limit access to land. Land can also be 


\section{Urmilla Bob and Salomé Bronkhorst}

used as a tool for manipulation by those with power. Moodley et al. (2010) for example emphasise the key role that land played in the Rwandan genocide. Land was not the primary reason for the genocide, but became a tool whereby ordinary citizens, whose livelihoods were increasingly vulnerable because of shrinking sizes of land, were incited to kill and take their neighbour's land and belongings. The authors also highlight the vicious feedback circles where the genocide led to environmental degradation and deforestation, in turn creating tensions.

\section{Water conflicts}

Klare (2001:57, cited in Gleditsch et al. 2006:362) states that by 2050 the increased demand for water could produce intense competition for this essential substance in all but a few well-watered areas of the planet'. Countries that share rivers therefore have a higher risk of military disputes or water wars (Gleditsch et al. 2006:361). Furthermore, several countries rely on water sources from outside their boundaries. Local and international competition over water resources will increase. This is likely to have impacts on national security as well as threaten livelihoods at the local level. The water itself is not only a source of conflict, but the resources in the water bodies, specifically fish, are also points of contestation. This is particularly relevant in contexts where communities or countries share boundaries. The problems are likely to be worse in contexts where boundaries are not clear and there are competing claims for resources. For example, Onuoha (2008:35) illustrates how environmental degradation and in particular diminishing water resources in Lake Chad has created conflicts and undermined livelihood sustaining activities in Cameroon, Chad, Niger and Nigeria. The study specifically highlights conflicts between and among fishermen, pastoralists, farmers and in some cases state security agents. Furthermore, Onuoha (2008:35) underscores the implications of conflicts that often degenerated into large-scale intra-ethnic, intra-state and inter-state conflicts.

Water conflicts are also directly linked to food security and the provision

of fresh water. Water is a crucial resource for agricultural productivity and contestations over water rights and access can (and do) undermine agricultural 


\section{Environmental conflicts: Key issues and management implications}

productivity levels. Furthermore, water degradation and conflicts are also linked to the migration of biodiversity (including people). For example, the migration of people in search of better sources of water is a widespread phenomenon in Africa. In the northeast of Tanzania (Pangani River Basin) migration has led to the convergence of pastoralists and farmers and to rapid population increases of both human beings and livestock (Mbonile 2005:41). Intensive water conflicts were caused, in which different irrigation systems (traditional and modern large-scale types) and uses of water (as hydropower generation) also played roles.

Climate change, discussed next, is deemed to intensify environmental conflicts and is inducing new forms of environmental conflicts.

\section{Climate change and environmental conflicts}

It is now widely recognised that climate change is having and will have significant impacts on social, economic and ecological systems and processes as socio-economic inequalities widen locally as well as globally (Intergovernmental Panel on Climate Change, IPCC, 2007). Thomas and Twyman (2005:122) state that an examination of climate change needs to include the relationships between global processes (including emission effects and international conventions), national responses and local outcomes, and particularly the effects of national decisions and policies on local opportunities and abilities to adapt. Thus, aspects relating to environmental conflicts are important to consider. Steffen et al. (2004:16) identify a range of proximate/direct (immediate human activities that drive a particular change) and underlying (fundamental needs and desires of individuals and groups) drivers affecting the natural environment and intensifying climate change. The direct drivers of human activities associated with climate change are land clearing (especially removal of forests/ natural ecosystems) and land cover conversion, introduction of alien species, agricultural practices, fossil fuel and biomass burning, and poor water use and management practices (including groundwater removal). The underlying human-induced drivers include an increase in demand for a wide range of goods and services including basic needs (food, water, clothing, shelter, health and 


\section{Urmilla Bob and Salomé Bronkhorst}

employment), transport, recreation and leisure activities, safety and security, and entertainment and luxury items.

The impacts of climate change on socio-political systems are not new. For example, Davis (2001, cited in Barnett and Adger 2007:641) shows how the El Niño events and famines of the $19^{\text {th }}$ century, triggered by droughts, resulted in political and economic colonisation that deprived local people of their entitlements to natural resources. Barnett and Adger (2007:642) further argue that it is important to consider how violent conflict is itself a powerful cause of human insecurity and vulnerability to climate change. Thomas and Twyman (2005:115) identify the implications of climate change for equity and justice among vulnerable groups at local and sub-national levels. Equity and justice, they assert, are important to consider because the poorest and most vulnerable groups (especially in developing countries where natural resource dependency is high) will disproportionately experience the negative effects of climate change.

Barnett and Adger (2007:639) state that climate change is increasingly being called a 'security' problem because there is concern that climate change may increase the risk of violent conflict. The underlying proposition is that climate change is likely to undermine human security by reducing the natural resource base and limiting access to existing natural resources which are central to sustainable livelihoods, especially in developing contexts as indicated earlier. In specific contexts, direct and indirect impacts of climate change on human security may in turn increase the risk of violent conflict (Barnett \& Adger 2007:639). Nordås and Gleditsch (2007:627) state that conflict-inducing effects of climate change have emerged in the literature and although several causal chains and/or paths to these conflicts have been suggested, there is a gap in terms of providing substantial evidence for these claims.

This point is mirrored in Omolo's (2010) empirical study in this issue. In light of increased droughts in the area, and given that livestock forms the foundation for food security in Kenya, competition over grazing land and water has increased, leading to violence. While the author reports that people have adopted a number of coping strategies to deal with climatic variability, 


\section{Environmental conflicts: Key issues and management implications}

such as diversification into agriculture, vulnerability is intensified because of an increase in militarised cattle raiding, attributed in part to economic decline in the Horn of Africa. Moreover, Reuveny (2007:656) illustrates that climate change-induced migration (referred to as environmental migration), which is likely to be more frequent given the increase in extreme weather events, can create and intensify violent conflicts. This will be particularly acute in lesser developed countries where, because of limited options to adapt to or mitigate climate change, people are more likely to leave affected areas. The Christian Aid Charity (cited in Nordås and Gleditsch 2007:629) warns that ' 184 million people could die in Africa alone as a result of climate change by the end of the $21^{\text {st }}$ century' and that 'at least one billion people will be forced from home as the effects of climate deepen an already burgeoning global migration crisis'.

While fundamental environmental factors for environmental migration are land degradation, droughts, deforestation, water scarcity, floods, storms and famines linked to food insecurity (Reuveny 2007:662), environmental migration can also result from development. In this issue, Jaggernath (2010) finds that nearly $78 \%$ of residents in the SDB would move out of the area if they received compensation and could move closer to their work. Omolo (2010) highlights that women from pastoral communities are often forced to move to cities during times of environmental stress and that some have turned to prostitution for survival.

\section{Managing environmental conflicts}

Environmentally related conflicts are linked to political, economic, social and ecological contexts. Very few studies or intervention strategies to address these conflicts adopt an integrated and interdisciplinary approach. Rather, one aspect is focused on in a fragmented manner and the others are neglected. However, it is important to emphasise that a focus on 'conflict' underscores the social and political aspects. The power dynamics and social components are crucial. Not all environmental conflicts have negative impacts, however. Conflicts can be important focal points to highlight social, economic and environmental problems. For example, from an ecological perspective, conflicts can draw attention to environmental problems and result in conservation efforts. White 


\section{Urmilla Bob and Salomé Bronkhorst}

et al. (2009:243) state that conflict management is necessary to reduce negative impacts (and promote positive effects).

While planning is a prerequisite for effective management and implementation in any context, it often remains an ideal rather than a reality (Paterson 2007:4). Ahmed (2008:45) reveals that although environmental concerns and agendas are increasing and management is being advocated by governments worldwide, current approaches remain regional, sectoral and unsustainable despite the proliferation of international policies and treaties. Furthermore, improper land use planning and ineffective implementation of policies are worsening the situation and contributing to ad hoc (and often inappropriate) interventions. This has devastating impacts on the biophysical environment and the long-term sustainability of the environment. Additionally, the impacts on people, especially the poor and vulnerable, can be dire. Environmental Impact Assessments, Social Impact Assessments and Strategic Environmental Assessments remain important legal and procedural tools to manage the environment, particularly with regard to current and intended development. However, the implementation of these tools requires due consideration for a range of factors, some of which are summarised below as broader recommendations for managing environmental conflicts.

\section{Recommendations}

Information management and knowledge production is an important component of conflict management. This article and this issue have shown that several aspects relating to environmental conflicts (especially in relation to climate change and the impacts on women) remain under-researched. Specifically, Nordås and Gleditsch (2007:633-634) propose five areas that need further examination in relation to climate-conflict relationships that are relevant to environmental conflicts more generally:

- Examining scientifically the interface between climate change models and conflict models including geographic variations, rates of change and adaptive measures. 


\section{Environmental conflicts: Key issues and management implications}

- Considering and specifying what types of violence are likely to result from climate change. This will require conflict monitoring.

- Balancing the positive and negative effects of climate change as well as the effects of various strategies of adaptation.

- Continuing to disaggregate the effects of climate change in systematic conflict models (in relation to geographical variations and types of change) to ascertain differing outcomes.

- Focusing on national security issues in both developing and developed countries. The construction of security scenarios is also advocated.

It is important, as Timura (2001:104) indicates, to incorporate the social and cultural nature of environmental conflicts such as the roles that social histories, symbolically mediated perceptions, and local political economics play in the outbreak of violence. Wittmer et al. (2006:5) present criteria which can address both ecological and social complexities for selecting instruments/ approaches to resolve environmental conflicts. They include pertinent information, legitimacy, social dynamics and costs.

White et al. (2009:243) argue that existing approaches to addressing natural resource conflicts have regional differences with developed countries largely adopting a structured legal framework, usually financed by public agencies, while in developing countries conflicts are addressed through case-specific approaches. They propose an integrated and functionally applied (based on indicators) framework to understand conflict dynamics and inform models that are capable of describing spatio-temporal aspects in different contexts to provide decision support for biodiversity management. Furthermore, a participatory analytical and management approach is advocated. The use of appropriate indicators is particularly useful in assessing the effectiveness of a specific intervention or management strategy as well as providing a basis for the identification of best practices.

Gender sensitive climate change and environmental management policy is essential. This issue highlights the need for integrated approaches to natural resource management and conflict resolution that take into account the vulnerabilities and rights of women. Perry et al. (2010) discuss a number of 


\section{Urmilla Bob and Salomé Bronkhorst}

interesting strategies devised by women in order to deal with the effects of and take action in environmental conflicts which include advocacy, travelling and staying in groups, and avoidance techniques. The strategies, according to the authors, appear to be entirely contextual, based inter alia on the socioeconomic, political and cultural environment, and the level at which they are implemented. While women's participation in local stakeholder forums on resource conflicts appears to be crucial and clearly invaluable, the authors highlight that often women are excluded and that peace negotiations are often dictated by men. Omolo (2010) argues that there are ways to better manage common grazing lands, reduce the vulnerability of pastoralists and to help the vulnerable (especially women) adapt. The author calls inter alia for coordinated, informed and gender sensitive policy making and implementation; better management of common grazing lands; the creation of gender sensitive safety nets for times of environmental stress, such as livestock insurance and credit facilities; and assistance to help pastoralists diversify their livelihoods.

Environmental management and environmental protection should balance the needs and interests of the environment, the people and especially the vulnerable. Targeted, flexible, well-informed and contextual approaches to NRM and conflict resolution are necessary. This should go hand in hand with helping those dependent on the environment to develop independent capacity to withstand shocks resulting from environmental change. While the separation between the ecological system and governance systems (decisions people make on how to manage and use the environment) is artificial (Bob 2008:12), 'humans should be considered as an integral and interdependent part of the global ecological system' (Ashton et al. 2005:450). In this issue, Okech (2010) argues that if NRM policies on conservation in particular are not formulated and implemented in a way that balances the needs and interests of conservation and people, it can lead to conflict. The Kenya case highlights the

plight of pastoralists in the Horn of Africa and especially the importance of partnerships in addressing these challenges. Ahmed (2010) also highlights that Integrated Coastal Zone Management (ICZM) is a useful administrative and policy tool for sustainably managing coastal zones and any conflicts. However, key challenges relate mainly to management, a lack of political buy-in and 


\section{Environmental conflicts: Key issues and management implications}

weaknesses in how information is presented to policy makers and those implementing them. The author also highlights the importance of ensuring stakeholder input and engagement and warns that if these challenges are not addressed, conflicts in coastal areas may increase, especially as a result of climate change and greater economic and population growth.

Narrow environmental protection efforts that do not consider and engage with the dynamics beyond particular borders (be it that of parks or countries) are at best short-sighted, and at worst, can lead to attacks on biodiversity, and to violence and poverty. Biodiversity issues often are viewed as being part of government agendas, but governments frequently lack the political will and/or resources required to protect the environment. While geographical boundaries exist to demarcate nation states, the location and movement of nature (including flora, fauna, air, water, pollutants and pests) are influenced by natural forces and processes that are not restricted to person-made boundaries (Bob et al. 2008:24). Furthermore, human mobility has also increased the movement of certain species of plants and animals. The case of Kenya in this issue is a good example.

Yasmi et al. (2006:538) emphasise the importance of achieving constructive conflict resolution in NRM and highlight the importance of local government structures and traditional leaders in managing conflicts in developing contexts. Community-based approaches to NRM and conflict resolution are deemed to be useful, particularly to promote locally based, indigenous management strategies. There is also increased attention in the literature to human intervention and technology in the overall management of environmental risks and conflicts (Mubareka and Ehrlich 2010; Raleigh and Urdal 2007). Specific approaches to effectively address environmental conflicts or manage environmental impacts of other forms of conflict are advocated which include environmental education programmes, environmental legislation/policy interventions, and the use of spatial technologies such as remote sensing and the Geographic Information System (GIS).

Planning and management of land activities should take into account environmental, social, political and other aspects. Bob (2010) in the article on 


\section{Urmilla Bob and Salomé Bronkhorst}

land conflicts advocates for land registration supported by adequate conflict resolution measures, and for land management and even psycho-social approaches to conflict. The author also stresses that communal land administration should remain under the ownership of communities and advocates for a contextual approach in communal land tenure. Addressing vulnerability and increasing the resilience of communities in order to prevent land conflicts and increase human security are essential. Finally, the author stresses the need for gender sensitive approaches and the valuable role that women's organisations can play in dealing with land conflicts.

Post-conflict peacebuilding processes should take into account the effect a conflict had on the environment and the stresses on the environment and people in the post-conflict period. In post-conflict situations there is a need for a long-term vision for sustainable development to balance environmental and social objectives and in particular to address vulnerability, unemployment and population growth. The impacts of the Rwandan genocide, as highlighted by Moodley et al. (2010), include a loss of biodiversity as a result of deforestation, the clearing of wetlands, clearing of conservation areas, and government housing policies. The authors argue that these are the results of the sheer number of returnees and refugees that need to be accommodated, and of the population density and resulting stresses on livelihoods, partly as a result of the genocide. Another key issue is the burning of fossil fuels for energy by $90 \%$ of Rwandans. Integrated forms of environmental management and a renewed focus on the development of affordable green technologies for use by poor households are essential to safeguard Rwanda's remaining environmental endowments for its people and posterity.

The importance of accountability, communication and governance is also an important aspect raised in this issue. Key aspects that emerged in Jaggernath's (2010) study in the SDB are that industry needs to be accountable to local residents, who pay the price for development but see few of the benefits. In addition to better communication and consultation on new developments and allaying health fears, the study finds that industries should show a greater commitment to Corporate Social Responsibility, and give benefits back to the community in the form of reserved jobs and community development. 


\section{Environmental conflicts: Key issues and management implications}

While only briefly touched upon, the study also shows a clear need for greater engagement by local government in NRM and in dealing with conflicts. It is unclear what role local civil society organisations play in the area, but it would be instructive to investigate what role they do or can play.

\section{Conclusion}

Environmental conflicts take on different forms and have multiple and varying impacts in different contexts. In particular, key points of conflict are in relation to climate change, conservation, water quality and availability, air quality and management aspects. Furthermore, a disconcerting trend is the migration levels associated with environmental and other conflicts that often result in existing or new conflicts emerging in receiving areas.

The matter of vulnerability remains an important aspect of understanding environmental conflicts. This issue highlights that the poor, marginalised groups and especially women are more likely to be impacted by environmental degradation and conflicts, whatever their types. In turn the poor are often dependent on environmental resources for livelihoods and energy - leading to environmental degradation. Furthermore, environmental degradation and diminishing environmental resources are linked to several conflicts from international to intra-national/local levels. However, what is a neglected field of research is the extent to which conflicts result in environmental degradation. Wars and other types of violence (such as invasions and destruction of property) can denude the natural resource base in terms of quality and/ or quantity. This in turn causes further tensions and conflicts as resources become scarce. In particular, the vulnerable, the poor and especially women who remain reliant on the natural resource base in developing contexts are most likely to be affected. Thus, this cycle contributes to both an increase in poverty and vulnerability as well as environmental degradation. The natural resource base is in itself extremely vulnerable during periods of conflict and becomes the focus for looting and exploitation. Also, as Le Billon (2001:561) states, 'resources not only financed, but in some cases motivated conflicts, and shaped strategies of power on the commercialisation of armed conflict'. The impacts of climate change are likely to worsen this situation and make 


\section{Urmilla Bob and Salomé Bronkhorst}

environmental conflicts phenomena that are more widespread globally. It is therefore imperative that environmental conflict dynamics are studied and appropriate resolution and management strategies employed to reduce these.

Environmental conflicts and/or threats of conflicts are emerging as critical issues for security and conflict research. These types of conflict also influence political processes and pose unique challenges in relation to how they are managed, including how government structures anticipate points of stress and insecurity. The magnitude and diversity of environmental conflicts and related risks are complex and have significant implications for the stability of natural, social, political and economic contexts and locations. Thus, environmental conflicts can threaten nature and social security.

\section{Sources}

ACCORD. 2002. Transforming conflict. Facilitator's reference manual. Durban, ACCORD.

Ahmed, F. 2008. Development pressures and management constraints in the coastal zone. Alternation, 15 (1), pp. 45-65.

Ahmed, F. 2010. Approaches to and tools for managing environmental conflicts in coastal zones in Africa: Challenges and prospects in relation to Integrated Coastal Zone Management (ICZM). African Journal on Conflict Resolution, 10 (2), pp. 31-47.

Ashton, P.J., M.J. Patrick, H.M. MacKay and A.V.B. Weaver 2005. Integrating biodiversity concepts with good governance to support water resources management in South Africa. Water SA, 31 (4), pp. 449-455.

Barnett, J. and W.N. Adger 2007. Climate change, human security and violent conflict. Political Geography, 26, pp. 639-655.

Barrett, C.B., D.R. Lee and J.P. McPeak 2005. Institutional arrangements for rural poverty reduction and resource conservation. World Development, 33 (2), pp. 193-197.

Bob, U. 2008. Introduction: Nature and people. Alternation, 15 (1), pp. 1-16.

Bob, U. 2010. Land-related conflicts in Sub-Saharan Africa. African Journal on Conflict Resolution, 10 (2), pp. 49-64.

Bob, U., K. Swart, B. Maharaj and P. Louw 2008. Nature, people and the environment: Overview of selected issues. Alternation, 15 (1), pp. 17-44.

Castro, A.P. and E. Nielson 2003. Natural resource conflict management case studies: An analysis of power, participation and protected areas. Rome, Food and Agriculture Organisation (FAO). 


\section{Environmental conflicts: Key issues and management implications}

Gerber, J-F., S. Veuthey and J. Martínez-Alier 2009. Linking political ecology with ecological economic in tree plantation conflicts in Cameroon and Ecuador. Ecological Economics, 68, pp. 2885-2889.

Gleditsch, N.P., K. Furlong, H. Hegre, B. Lacina and T. Owen 2006. Conflicts over shared rivers: Resource scarcity or fuzzy boundaries. Political Geography, 25, pp. 361-382.

Hardin, G. 1968. The Tragedy of the Commons. Science, 162 (3859), pp. 1243-1248. Available from: <http://www.garretthardinsociety.org/articles/art_tragedy_of_the_commons. html>

Hellström, E. 2001. Conflict cultures - qualitative comparative analysis of environmental conflicts in forestry. Silva Fennica Monographs 2. Helsinki, The Finnish Society of Forest Science and The Finnish Research Institute.

Hubbard, P., R. Kitchin, B., Bartley and D. Fuller 2002. Thinking Geographically. London, Continuum.

Intergovernmental Panel on Climate Change (IPCC) 2007. IPCC Fourth Assessment Report - Working Group 111 Report 'Mitigation of Climate Change'. Available from: <http:// www1.ipcc.ch/ipccreports/ar4-wg3.htm>.

Jaggernath, J. 2010. Environmental conflicts in the South Durban Basin: Integrating residents' perceptions and concerns resulting from air pollution. African Journal on Conflict Resolution, 10 (2), pp. 137-152.

Kok, A., W. Lotze and S. van Jaarsveld 2009. Natural resources, the environment and conflicts. African Centre for the Constructive Resolution of Disputes (ACCORD). Available from: $<$ www.accord.org.za> [Accessed 16 March 2009].

Le Billon, P. 2001. The political ecology of war: Natural resources and armed conflicts. Political Geography, 20, pp. 561-584.

Le Maitre, D., P.J. O’Farrell and B. Reyers 2007. Ecosystem services in South Africa: A research theme that can engage environmental, economic and social scientists in the development of sustainability science. South African Journal of Science, 103, pp. 367-376.

Mbonile, M.J. 2005. Migration and intensification of water conflicts in the Pangani Basin, Tanzania. Habitat International, 29, pp. 41-67.

Mix, T.L. and T.E. Shriver 2007. Neighbours, nuisances and noxious releases: Community conflict and environmental hazards in the atomic city. The Social Science Journal, 44, pp. 630-644.

Moodley, V., A. Gahima and S. Munien 2010. Environmental causes and impacts of the genocide in Rwanda: Case studies of the towns of Butare and Cyangugu. African Journal on Conflict Resolution, 10 (2), pp. 103-119.

Mubareka, S. and D. Ehrlich 2010. Identifying and modelling environmental indicators for assessing population vulnerability to conflict using ground and satellite data. Ecological Indicators, 10, pp. 493-503. 


\section{Urmilla Bob and Salomé Bronkhorst}

Nordås, R. and N.P. Gleditsch 2007. Climate change and conflict. Political Geography, 26, pp. 627-638.

Okech, R. 2010. Wildlife-community conflicts in conservation areas in Kenya. African Journal on Conflict Resolution, 10 (2), pp. 65-80.

Omolo, N.A. 2010. Gender and climate change induced conflict in pastoral communities: case study of Turkana in north-western Kenya. African Journal on Conflict Resolution, 10 (2), pp. 81-102.

Onuoha, F.C. 2008. Environmental degradation, livelihoods and conflicts: A focus on the implications of the diminishing water resources of Lake Chad for North-Eastern Nigeria. African Journal on Conflict Resolution, 8 (2), pp. 35-62.

Paterson, A. 2007. Wandering about South Africa’s new Protected Areas Regime. SA Public Law, 22 (1), pp. 1-33.

Perry, E., C. Potgieter and U. Bob 2010. Environmental conflicts and women's vulnerability in Africa. African Journal on Conflict Resolution, 10 (2), pp. 121-136

Raleigh, C. and H. Urdal 2007. Climate change, environmental degradation and armed conflict. Political Geography, 26, pp. 674-694.

Reuveny, R. 2007. Climate change-induced migration and violent conflict. Political Geography, 26, pp. 656-673.

Steffen, W., A. Sanderson, P. Tyson, J. Jager, P. Matson, B. Moore III, F. Oldfield, K. Richardson, J. Schellnhuber, B.L. Turner II and R. Wasson 2004. Global change and the Earth system: A planet under pressure - Executive summary. New York, Springer.

Thomas, D.S.G. and C. Twyman 2005. Equity and justice in climate change adaptation amongst natural-resource-dependent Societies. Global Environmental Change, 15, pp. 115-124.

Timura, C.T. 2001. 'Environmental conflict' and the social life of environmental security discourse. Anthropological Quarterly, 74 (3), pp. 104-113.

Wallensteen, P. 2007. Understanding conflict resolution. London, Sage.

White, R.M., A. Fischer, K. Marshall, J.M.J. Travis, T.J. Webb, S. di Falco, S.M. Redpath, and E. van der Wal 2009. Developing an integrated conceptual framework to understand biodiversity conflicts. Land Use Policy, 26, pp. 242-253.

Wittmer, H., F. Rauschmayer and B. Klauer 2006. How to select instruments for the resolution of environmental conflicts. Land Use Policy, 23, pp. 1-9.

Yasmi, Y., H. Schanz and A. Salim 2006. Manifestation of conflict escalation in natural resource management. Environmental Science and Policy, 9, pp. 538-546. 